\title{
Why the Real Thing Is Essential for Telling Our Stories
}

\author{
David Demant \\ Senior Curator Information and Communication, \\ Museum Victoria, GPO Box 666, Melbourne, Victoria 3001, Australia \\ ddemant@museum.vic.gov.au
}

\begin{abstract}
Museum Victoria possesses the only intact first generation electronic stored program computer left in the world. Real things, like CSIRAC, are entry portals to a past era. Along with contemporary documents and records, they are the closest we can get to time travel. They complement historical records. Historical records are not substitutes for the real thing, neither are replicas or facsimiles. We use real objects in combination with historical and contemporary knowledge to develop our understanding of the past. The presentation answers the question implied by the title 'Why the real thing is essential for telling our stories" 'in two ways. First, it discusses what we and future generations gain by conserving and interpreting the real thing on an on-going basis. Second, it gives examples from the museological work done with CSIRAC and its archive.
\end{abstract}

Keywords: first-generation; stored-program; electronic; computer; software; CSIRAC; objects; real-thing; facsimiles; replicas; museum; archive.

\section{Museum Victoria}

Museum Victoria possesses the only intact first generation electronic stored program computer left in the world.

It is a real thing, not a replica. It was the first computer in Australia, fourth in the world. It is complemented by a complete archive of software, documentation, paperwork and drawings - also all real things.

Real things are Rosetta stones - entry portals to a past era. Along with contemporary documents and records, they are the closest we can get to time travel. They complement historical records; they are not substitutes.

What do real things like CSIRAC and its archive share with the Rosetta Stone? The Rosetta Stone enabled us to recover information coded in Egyptian hieroglyphs. This knowledge had been lost for over 1300 years. The Stone has inscribed upon it a single text written in three different inscriptions, one of which is hieroglyphics. The representation of this text in three scripts, combined with contemporary understandings and knowledge, enabled scholars to decipher the hieroglyphs. The story of the Rosetta Stone gives us hope that 'lost' information can be recovered.

For the purposes of this paper, the story of Rosetta Stone has another important lesson. The analysis of the Stone led to the discovery that the hieroglyphic language is more than a pictorial representation of ideas; that it is a spoken language with more information embedded in it than just images. The analysis revealed more of the 
knowledge embedded in the hieroglyphs than was expected when the analysis was initiated. In the same way, preserving the real thing may enable future generations with insights that are beyond our current state of knowledge.

We need real objects in combination with historical and contemporary knowledge to develop our understanding of the past. Our understanding of the past prepares us better to deal with the present and the future.

\section{CSIRAC}

Examples will be given from the work done with CSIRAC and its archive that illustrate the value of preserving the real thing compared to replicas and facsimiles. Replicas and facsimiles generally reproduce only a few aspects of an item and even those are not necessarily reproduced accurately or completely.

The work referred to was carried out by the CSIRAC History Team ${ }^{1}$, which includes former operators and users of CSIRAC. The examples involve the extensive paper tape archive of mainly 12-hole and 5-hole punched paper tapes. This includes the CSIRAC Library tapes, which held a group of tried, tested and documented programs. There are program listings for each tape in the CSIRAC paper tape Library but other tapes were not so well blessed as regards testing and documentation.

The first example of the value of the real thing deals with the translation into electronic form of the programs punched into the original paper tapes, whether they were part of the Library or not. The equipment to do this archival work was specially designed to read the original programs (punched into the paper tape); the equipment to read paper tape was calibrated using an original manual paper tape punch, part of the CSIRAC museum collection. The existence of the original tapes and/or listing ensured accuracy of the content of the tapes. One of the incentives for this work was the desire to recreate the music of CSIRAC. CSIRAC was the first electronic computer to be programmed to generate music, in 1951.

The second example involves an accidental discovery. A further tape that was acquired fortuitously from the private collection of one of the CSIRAC pioneers, ${ }^{2}$ provided the basis for the rewriting of an existing incomplete (and in part erroneous) program. The result was a correct and executable program. This would not have been possible without that tape. This shows that a combination of original artifacts, expertise and historical records can provide new insights.

The important thing is that these examples show that information can be resurrected rather than indicating the value of the information. The value of an original item may not be apparent initially; indeed one can never be sure what insights it may later provide.

The presentation will also include a history of CSIRAC from its development phase in Sydney through its operational phase in Melbourne to its current role as an

${ }^{1}$ The CSIRAC History Team is part of The University of Melbourne and works closely with Museum Victoria.

${ }^{2}$ The pioneer referred to was Dr. Frank Hirst, who headed the Computational Laboratory at the University of Melbourne. CSIRAC was transferred to The University of Melbourne in 1955 under the care of Dr Hirst. Its arrival enabled the University to establish one of the earliest Computer Science departments in the world. 
icon of digital technology in Museum Victoria. It has become a symbolic milestone in the human journey.

CSIRAC is the abbreviation for Commonwealth Scientific and Industrial Research organisation Automatic Computer and is pronounced 'sigh-rack'. It was developed in Sydney and, in November 1949, it ran its first test program. In 1955, it was transported to Melbourne and, from 1956 to 1964; it provided a computing service for science and industry. In 1964, it was switched off for the final time and donated to Museum Victoria. It is currently on long-term display at Melbourne Museum.

For more information about CSIRAC, please visit:

http://museumvictoria.com.au/csirac/

http://www.csse.unimelb.edu.au/dept/about/csirac/

\section{References}

1. Beard, M., Pearcey, T.: The Genesis of an Early Stored-Program Computer: CSIRAC. IEEE Annals of the History of Computing (IEEE) 6(2), 106-115 (1984)

2. Deane, J.: CSIRAC: Australia's first computer, 45 p. Australian Computer Museum Society (1997), ISBN: 0-6463-4081-6

3. Demant, D.: The first computer mouse. Museum Victoria (2001), ISBN: 0731184211

4. Doornbusch, P.: The Music of CSIRAC, Australia's first computer music. Common Ground (2005), ISBN: 1-86335-569-3

5. McCann, D., Thorne, P.: The Last of The First, CSIRAC: Australias First Computer. University of Melbourne Computing Science (2000), ISBN: 0-7340-2024-4

6. Pearcey, T.: A History of Australian Computing, 192 p. Chisholm Institute of Technology (1988), ISBN: 0947186948 